\title{
РОССИЯ И ЕС: СОТРУДНИЧЕСТВО В ПРАВООХРАНИТЕЛЬНОЙ СФЕРЕ
}

Проблема развития отношений между Россией и Европейским Союзом в сфере борьбы с преступностью является предметом обсуждения уже много лет. Однако уровень развития этих отношений до сих пор остается на достаточно низком уровне. Сотрудничество между России и Европейским Союзом в правоохранительной сфере развивается очень медленно, несмотря на крайнюю необходимость плодотворного диалога. ${ }^{1}$

Уровень международного сотрудничества в той или иной области всегда является отражением внутренних особенностей соответствующей политики ${ }^{2}$. До последнего времени (до 01 декабря 2009 года) вопросы сотрудничества в сфере борьбы с преступностью в рамках ЕС относились к т.н. третьей опоре Европейского Союза. Решения, рамочные решения и иные акты, принимаемые в рамках третьей опоры, обязательны для государств - членов ЕС, но не имеют в каждом государстве прямой юридической силы ${ }^{3}$.

Принимая во внимание достаточно низкий уровень интеграции в правоохранительной сфере внутри ЕС развивать полноценное сотрудничество между Европейским Союзом и третьими странами было весьма проблематично.

Говоря о международном сотрудничестве ЕС в правоохранительной сфере следует выделить два уровня такого сотрудничества: наднациональный (на уровне ЕС - третье государство) и национальный двухсторонние отношения государства - члена ЕС с третьим государством). При этом акцент явно смещен в пользу второй уровня сотрудничества.

\footnotetext{
1 См. Potemkina O. Russia's Engagement with Justice and Home Affairs: a question of Mutual Trust. Brussels, CEPC, 2002.

2 SANDRA LAVENEX \& NICOLE WICHMANN, The External Governance of EU Internal Security, European Integration Vol. 31, No. 1, 83-102, January 2009

3 Подробнее о правовых актах, принимаемых в рамках третьей опоры см.: Peers Steve, EU Justice and home affairs law, Essex, 2000.
} 
Российская Федерация развивает сотрудничество в правоохранительной сфере по обоим направлениям. В настоящее время между Россией и странами, входящими в состав Европейского союза, существует ряд механизмов, позволяющих осуществлять сотрудничество в правоохранительной сфере. К таким механизмам следует отнести ряд двухсторонних соглашений о правовой помощи по уголовным делам, многосторонних конвенций, соглашений между правоохранительными органами и т.д. ${ }^{4}$ Вместе с тем, уровень такого сотрудничества не всегда позволяет в полной мере противостоять современной организованной преступности.

Очевидно, что международная практика борьбы с организованной преступностью требует развития не только межгосударственных отношений, но и взаимоотношений на уровне существующих наднациональных институтов.

Регулятивная основа сотрудничества России и Европейского Союза в правоохранительной сфере на наднациональном уровне представлена в виде международных соглашений и актов мягкого права. К таким документам следует отнести, в частности, Соглашение о партнерстве и сотрудничестве, 1994 $\Gamma^{5}$, соглашение о стратегическом сотрудничестве с Европолом, План действий Европейского Союза по отношении к России в сфере борьбы с организованной преступностью, $2000^{6}$, а также ряд совместных заявлений ${ }^{7}$, дорожная карта по общему пространству свободы, безопасности и правосудия.

Однако указанные документы не составляют необходимую юридическую основу для полноценного сотрудничества между сторонами. В большей степени они являются неким ориентиром, соглашениями о намерениях.

При этом в соответствии со Стокгольмской программой (п. 7.5.) $)^{8}$ Россия наряду с США является основными стратегическими партнерами ЕС в области пространства свободы, безопасности и правосудия.

В целом, сотрудничество России и Европейского Союза в правоохранительной сфере можно условно разделить на три направления:

4 См. Договор между Российской Федерацией и Королевством Испания об оказании правовой помощи по уголовным делам, Москве 25 марта 1996 года. Ратифицирован Федеральным законом РФ от 8.10.2000 г.? 127-Ф3, Европейская конвенция от 13.12.1957 г. о выдаче // Собрание законодательства РФ. 5 июня 2000 г. N 23. Ст. 2348, Европейская конвенция от 20.04.1959 г. о взаимной правовой помощи по уголовным делам //Собрание законодательства РФ. 5 июня 2000 г. N 23. Ст. 2349.

5 Соглашение о партнерстве и сотрудничестве, учреждающее партнерство между Российской Федерацией, с одной стороны, и Европейскими сообществами и их государствами-членами, с другой стороны, Корфу, 23.06.1994, http://www.eur.ru/neweur/user.php?func=apage\&id=17.

6 The Council of the European Union, European Union action plan on common action for the Russian Federation on combating organized crime (2000/C 106/02), Official Journal C 106, 13/04/2000 p. 0005-0012, перевод на русский http://www.eur.ru/neweur/show_file2.php?ident=13.

7 Совместное заявление о борьбе с терроризмом, принятое на Саммите Россия-ЕС 11.11.2002 г. в г. Брюсселе, http://www.eur.ru/neweur/summits/sum62 rus.doc

8 The Stockholm Programme - An open and secure Europe serving and protecting the citizens, Brussels, 2 December 2009, http://ec.europa.eu/justice_home/news/intro/doc/stockholm_program_en.pdf 
сотрудничество в полицейской сфере; правовое сотрудничество по уголовным делам; сотрудничество в сфере совершенствования правоохранительного законодательства и практики борьбы с преступностью.

В рамках настоящей статьи будут рассмотрены первые два направления, касающиеся полицейского сотрудничества и сотрудничеств в уголовнопроцессуальной деятельности.

Сотрудничество в сфере совершенствования правоохранительного законодательства и практики борьбы с преступностью представляет собой разноуровневую и разноплановую деятельность, поэтому данную проблематику целесообразно сделать предметом самостоятельного исследования.

Полицейское сотрудничество России и ЕС является той областью, которая развивается динамичнее остальных. В рамках полицейского сотрудничества можно выделить три основные составляющие: оперативное сотрудничество; техническое сотрудничество и научно-образовательное сотрудничество.

Ключевая роль в осуществлении полицейского сотрудничества между Россией и ЕС принадлежит взаимодействию с Европолом.

Европол является одной из наиболее эффективных организаций в правоохранительной сфере ЕС. В связи с этим развитию отношений с Европолом Россия уделяет особое значение.

В соответствии со статьей 23 Решения о создании Европола9 последний вправе заключать международные соглашения с третьими странами и международными организациями. При этом такие соглашения заключаются после одобрения со стороны Совета и при условии, если государство или международная организация, с которой планируется заключить соглашение, содержится в перечне, утвержденным решением Совета. Такое решение было принято 30 ноября 2009 года ${ }^{10}$. В перечень, утвержденный данным решением, входит 25 государств, в том числе Россия и три международные организации - Интерпол, Международная таможенная организация и управлением ООН по наркотикам и преступности.

Европол вправе заключать соглашения с третьими странами, предусматривающие обмен тремя видами информации: стратегическая, оперативная и техническая.

9 Council Decision 2009/371/JHA of 6 April 2009 establishing the European Police Office (Europol). Official Journal L 121 of 15.5 .2009 .

10 Council Decision 2009/935/JHA of 30 November 2009 determining the list of third States and organisations with which Europol shall conclude agreements, Official Journal L $325,11 / 12 / 2009$ P. 0012-0013. 
На сегодняшний момент в рамках ранее действовавшей Конвенции Европол уже заключил ряд соглашений с третьими странами и международными организациями, которые можно поделить на два вида: оперативные соглашения и стратегические. Первый вид соглашений предусматривает обмен информацией оперативного характера, в том числе персональными данными, второй вид соглашений предусматривает обмен информацией стратегического и технического характера.

Стратегические соглашения были заключены с такими странами и организациями, как Россия, Албания, Босния и Герцеговина, Колумбия, Бывшая Югославская Республика Македония, Молдова, Турция, Сербия, Черногория, Управление ООН по наркотикам и преступностью, Международная таможенная организация. Такие соглашения предусматривают обмен информацией о способах совершения преступления, каналах финансирования денег, полученных преступным путем, методы расследования преступления, обмен опытом, совместные тренинги и т.д.

Оперативные соглашения предусматривают возможность обмена не только оперативной и технической информацией и персональными данными, т.е. данными о конкретных лицах, которые в той или иной степени связаны с совершением определенных преступлений. Такие соглашения заключены с США, Канадой, Австралией, Хорватией, а также ассоциированными членами Шенгенского пространства - Исландия, Норвегия и Швейцария, Интерполом.

6 ноября 2003 года между Россией и Европолом было заключено соглашение о стратегическом сотрудничестве ${ }^{11}$. Однако, как было отмечено выше, указанное соглашение предусматривает лишь обмен технической о стратегической информации. Наличие с Европолом соглашения об оперативном сотрудничестве дает сторонам значительно большое преимущество в борьбе с преступностью, поскольку стороны получают возможность обмена информацией, собираемой и обрабатываемой в масштабах всего Союза. Поэтому Россия и ЕС уже давно ведут работу по заключению такого соглашения.

Переговоры по новому соглашению начались в октябре 2010 года, в июле 2011 года прошел уже третий раунд переговоров, предполагается, что соглашение будет подписано в 2012 году.

Однако и при отсутствии оперативного соглашения контакты между Европолом и Российскими правоохранительными органами развиваются достаточно интенсивно, несколько раз в год проводятся совместные семинары,

11 Соглашение о сотрудничестве между Российской Федерацией и Европейской полицейской организацией, режим электронного доступа: http://eu-law.ru/2011/06/coglashenie-mezhdu-rossiej-i-evropolom-2003-g/ 
курсы, оперативные совещания, обсуждаются такие темы, как подделка ЕВРО, защита свидетелей и т.д.

Научно-образовательное сотрудничество в правоохранительной сфере осуществляется главным образом по линии Европейского полицейского колледжа (CEPOL). Европейский полицейский колледж представляет собой агентство Европейского Союза, которое посредством научной и образовательной деятельности способствует повышению квалификации и увеличению уровня взаимодействия между офицерами полиции государств ЕС. Европейский полицейский колледж осуществляет также взаимодействие с научно-образовательными учреждениями третьих стран. Указанным направлением занимается рабочая группа по внешним сношениям (External Relations Working Group (ERWG).

В настоящее время стороны рассматривают возможные формы сотрудничества. Российская сторона предлагает заключить соглашение о сотрудничестве, которое бы закрепила формы и направления взаимодействия между Европейским полицейским колледжем и правоохранительными органами России. На сегодняшний момент сотрудничество между Россией и Европейским полицейским Колледжем осуществляется посредством проведения совместных конференций, взаимного участия в курсах повышения квалификации ${ }^{12}$ и т.д.

Особого внимания заслуживает проблема осуществления правовой помощи по уголовным делам. Данная сфера сотрудничества включает в себя, в первую очередь, выполнение запросов о производстве следственных действий, передачу доказательств, выдачу лиц, подозреваемых или осужденных за совершенное преступление (экстрадиция) и т.д.

Правовое сотрудничество между Россией и Европейским Союзом по уголовным делам осуществляет главным образом на национальном уровне посредством взаимодействия на уровне - государство-член ЕС. Вместе с тем, по мере развития сотрудничества в уголовно-процессуальной сфере внутри Союза все острее встает вопрос о развитии соответствующей договорной базы на уровне Россия и ЕС.

После вступления в силу Амстердамского договора Европейскому Союзу в силу статей 24 и 38 договора о ЕС было предоставлено право вести переговоры и заключать международные договоры в сфере полицейского и правового сотрудничества по уголовным делам. Иными словами, Европейский Союз в

12 Decision 12/2011/GB of the Governing Board of the European Police College written procedure for the participation of the EU Police Officers to two Courses organized by the Russian ministry of Interior of the Adopted by the Governing Board via written procedure on 8 April 2011, режим электронного доступа: http://www.cepol. europa.eu/fileadmin/website/About_CEPOL/Governing_Board/Governing_Board_Decisions/2011/2011_12.pdf 
рамках третьей опоры мог выступать в качестве стороны международного соглашения.

Первые такие соглашения были заключены в 2003 году. 25 июня 2003 года между ЕС и США были заключены два соглашения - соглашение об экстрадиции между Европейским Союзом и США ${ }^{13}$ и соглашение о взаимной помощи между Европейским Союзом и США ${ }^{14}$.

Указанные соглашения были заключены на основе существующих двухсторонних соглашений между государствами - членами ЕС и США. Основная задача соглашений, заключенных в 2003 году, состояла в том, чтобы унифицировать правила об оказании взаимной правовой помощи по уголовным делам и экстрадиции, действующие между государствами - членами ЕС и США.

Несмотря на то, что сторонами обоих соглашений являются США и ЕС, фактически они регулируют отношения, складывающиеся между отдельными государствами - членами ЕС, с одной стороны, и США, с другой. В связи с этим, оба соглашения могут быть расценены рамочный документ, в соответствии с которым государства члены ЕС и США должны привести свои двусторонние отношения посредством изменения существующих договоров или заключения нового договора.

Для вступления в силу обоих соглашений было необходимо выполнение двух требований. Во-первых, все государства - члены должны были обменяться соответствующими документами, подтверждающими имплементацию данного соглашения на двухстороннем уровне. Во-вторых, оба соглашения должны быть ратифицированы: со стороны США - ратификация соглашений от 25 июня 2003 года, а также ратификация всех двухсторонних соглашений между США и государствами - членами ЕC; со стороны ЕC ратификация в государствах - членах двухсторонних соглашений, а также ратификация соглашений от 25 июня 2003 года теми государствами, которые решили воспользоваться частью 5 статьи 24 договора о Европейском Союзе.

Данные процедуры были завершены к 2009 году. 7 апреля 2009 года Совет ЕС принял решение о заключении обоих соглашений, в соответствии с которым было подтверждено завершение процедуры «ратификации» ${ }^{15}$.

13 Agreement on extradition between the European Union and the United States of America, Official Journal L 181 , 19.7.2003, p. 27-33.

14 Agreement on mutual legal assistance between the European Union and the United States of America, Official Journal L 181, 19.7.2003, p. 34-42.

15 COUNCIL DECISION on the conclusion on behalf of the European Union of the Agreement on extradition between the European Union and the United States of America and the Agreement on mutual legal assistance between the European Union and the United States of America, Brussels, 7 April 2009, 7746/09, http://register.consilium.europa.eu/pdf/en/09/st07/st07746.en09.pdf 
Стороны обменялись «письменными документами», о ратификации и имплементации обоих соглашений на двухстороннем уровне в ходе министерской встречи по вопросам юстиции и внутренних дел 28 октября 2009 года. Соглашения вступили в законную силу 1 февраля 2010 года. Соглашения об экстрадиции и о правовой помощи между ЕС и США являются первыми и в течение длительного времени единственными соглашениями такого рода в сфере полицейского и правового сотрудничества по уголовным делам. В ноябре 2009 года соглашение о правовой помощи по уголовным делам было заключено еще с одним важным партнером ЕС - Японией ${ }^{16}$.

Очевидно, что правовое сотрудничество между Россией и ЕС также можно развивать посредством заключения соответствующих соглашений. В этом случае запрашиваемым и запрашивающим государствами будут Россия и соответствующее государство - член ЕС, однако последнее будет связано нормами, принятыми на наднациональном уровне. Запрос о правовой помощи, направленный РФ а адрес одного из членов ЕС, будет иметь одинаковую силу и для других государств ЕС, если это необходимо для его выполнения.

В настоящее время вопрос о заключении такого соглашения между Россией и ЕС находится в стадии обсуждения, однако конкретные сроки начала переговорного процесса пока не ясны.

Для повышения эффективности сотрудничества в соглашениях о правовой помощи по уголовным делам необходимо предусмотреть возможность вовлечения в процесс обмена правовой информации не только национальных правоохранительных органов, но и институтов Европейского Союза, таких, как Евроюст, на который возложена обязанность по осуществлению координации сотрудничества в сфере уголовного судопроизводства в рамках Европейского Союза. Учитывая, что Евроюст обладает необходимой инфраструктурой и возможностями быстрой координации деятельности правоохранительных органов стран - членов ЕС, то процедура оказания правовой помощи может быть значительно оптимизирована.

Согласно статье 26а решения Совета о создании Евроюста (в редакции решения от 16 декабря 2008 года ${ }^{17}$ ) Евроюст может устанавливать и развивать сотрудничество с третьими странами и международными организациями. Такое сотрудничество может предусматривать обмен информацией, в том числе персональными данными, оказание содействия в осуществлении правовой помощи по уголовным делам и т.д. Данное сотрудничество может базироваться

\footnotetext{
16 Agreement between the European Union and Japan on mutual legal assistance in criminal matters Official Journal L 39, 12.2.2010, p. 20-35.

17 Council Decision 2009/426/JHA of 16 December 2008 on the strengthening of Eurojust and amending Decision 2002/187/JHA setting up Eurojust with a view to reinforcing the fight against serious crime Official Journal L 138, 4.6.2009 p. $14-32$.
} 
на положениях международного соглашения, заключенного Евроюстом с третьим государством или международной организацией. На сегодняшний момент, кроме государств - ассоциированных участников Шенгенских соглашений, Евроюст заключил такие соглашения с двумя странами - США и Хорватией ${ }^{18}$.

Россия пока такого договора не имеет, однако сотрудничество, тем не менее, развивается. От Евроюста поступают заявки в адрес Генеральной Прокуратуры России по конкретным уголовным делам. Соглашение между РФ и Евроюстом находятся в стадии переговоров, по состоянию на июнь 2011 года прошло пять раундов переговоров, однако конкретные сроки завершения работ пока не ясны.

Процедура направления и выполнения запросов о правовой помощи должна быть сокращена по времени и упрощена по своей структуре. Иными словами, правоохранительные органы должны получать возможность направлять запросы напрямую в соответствующий орган иностранного государства или в Евроюст по дипломатическим или иным каналам, а запрашиваемая сторона обязана будет выполнить запрос в течение определенного времени. Причем сроки, порядок, ответственность сторон и иные процедурные вопросы должны быть отрегулированы соответствующими соглашениями.

18 http://www.eurojust.europa.eu/official_documents/Agreements/061106_EJ-US_co-operation_agreement.pdf 


\section{ROSJA I UNIA EUROPEJSKA: WSPÓŁPRACA W SFERZE OCHRONY PRAWNEJ}

Problem rozwoju współpracy UE z Rosją w sferze walki z przestępczością jest dyskutowany od wielu lat. Do chwili obecnej poziom rozwoju tej współpracy nie jest jednak zadawalający. Współpraca UE z państwami trzecimi w sferze ochrony prawnej realizowana jest na poziomie ponadnarodowym oraz międzyrządowym $\mathrm{z}$ akcentem na ten ostatni (współpraca poszczególnych państw członkowskich Unii z państwami trzecimi). Można wskazać trzy płaszczyzny współpracy Rosji i UE w przestrzeni bezpieczeństwa: współpraca policji, w sprawach karnych oraz zwalczania przestępczości (przyjmowanie stosownych aktów prawnych oraz praktyka). Szczególna rolę w ramach współpracy policji pełni współpraca rosyjskich służb z Europolem. Ważnym kierunkiem współpracy Rosji z UE jest ustanowienie pomocy prawnej w sprawach karnych. 


\section{RUSSIA AND THE EUROPEAN UNION: \\ COOPERATION IN THE SPHERE OF LEGAL PROTECTION}

The problem of the development of cooperation between the EU and Russia in the sphere of combating crime has been discussed for many years. Significant developments in this cooperation remain unsatisfactory. EU cooperation with third countries in the field of legal protection is implemented at supranational and intergovernmental levels with emphasis on the latter (cooperation between the member states of the Union with third countries). One can specify three areas of cooperation between Russia and the EU in the field of security: police cooperation, cooperation in criminal matters, and the combating of crimes (adoption of relevant legislation and practice). The particular role in the framework of cooperation is connected with the cooperation of Russian services with Europol. An important direction for Russia's cooperation with the EU is to establish legal assistance in criminal matters.

Key words:

Russia, legal protection, police cooperation, criminal matters, combating the crimes 